\title{
Diagnosing Immune Thrombocytopenia
}

\author{
Ulrich J. Sachs ${ }^{1,2}$ \\ ${ }^{1}$ Institute for Clinical Immunology and Transfusion Medicine, Justus \\ Liebig University, Giessen, Germany \\ ${ }^{2}$ Center for Transfusion Medicine and Haemotherapy, University \\ Hospital Giessen and Marburg, Marburg, Germany
}

Address for correspondence Ulrich J. Sachs, MD, PhD, Institute for Clinical Immunology and Transfusion Medicine, Justus Liebig University, Langhansstr. 7, 35392 Giessen, Germany (e-mail: Ulrich.sachs@med.uni-giessen.de).

Hämostaseologie 2019;39:250-258.

\begin{abstract}
Although the detection of a characteristic autoantibody can prove immune thrombocytopenia (ITP), this diagnosis is often based on the exclusion of other causes of thrombocytopenia. Direct glycoprotein (GP)-specific tests have the property required to demonstrate such a characteristic autoantibody. In contrast, platelet-associated immunoglobulin $G$ or antibody detection in plasma or serum is an insufficient diagnostic test. Moreover, data for commercial capture assays are sparse and their use is currently not recommended. A significant drawback of direct GP-specific tests is their low sensitivity, and a negative test result has no relevance. It is therefore also useful to establish a diagnosis of (primarily) hyperdestructive thrombocytopenia. A full blood count together with the immature platelet fraction has an excellent positive predictive value for ITP. Plasma glycocalicin has no apparent diagnostic value in identifying ITP patients, and conflicting data for TPO preclude its use for diagnostic purposes.

\section{Zusammenfassung}

Obwohl der Nachweis charakteristischer Autoantikörper eine Immunthrombozytopenie (ITP) sichern kann, wird die Diagnose oft auf der Basis des Ausschlusses anderer Ursachen einer Thrombozytopenie gestellt. Direkte glykoprotein (GP)-spezifische Tests besitzen die erforderliche Eigenschaft zum Nachweis charakteristischer ITP-Antikörper. Die Bestimmung von plättchen-assoziiertem IgG oder der Nachweis von Autoantikörpern aus Serum oder Plasma ist hingegen unzureichend. Zudem liegen nur spärliche Daten für die Verwendung kommerzieller Capture-Systeme vor, ihre Verwendung kann gegenwärtig nicht empfohlen werden. Ein relevanter Nachteil der direkten GP-spezifischen Tests ist ihre niedrige Sensitivität, ein negatives Testergebnis hat daher keine diagnostische Relevanz. Es ist daher auch sinnvoll, frühzeitig eine (primär) hyperdest-

Keywords

- platelet

- diagnosis

- autoantibodies ruktive Thrombozytopenie zu sichern. Ein Blutbild zusammen mit der immature platelet fraction hat einen sehr guten positiven prädiktiven Wert für die ITP. Die Studienergebnisse für Plasma-Glycocalicin und Thrombopoeitin sind unzureichend, ihre Verwendung als diagnostischer Marker kann momentan nicht empfohlen werden.
\end{abstract}

\section{Introduction}

Immune thrombocytopenia (ITP) is an autoimmune disease mediated by antiplatelet autoantibodies which are responsible for decreased platelet survival and, to some extent, suppressed platelet production. The diagnosis of ITP is often based on the

received

October 11, 2018

accepted after revision

January 8, 2019 exclusion of other causes of thrombocytopenia. ${ }^{1-3}$ It can be made in patients with platelet counts $<100 \mathrm{G} / \mathrm{L}$ who lack findings that suggest another diagnosis in their history, physical examination, full blood count and smear ( - Table 1 ). Although many guidelines consider further laboratory testing unnecessary, identifying alternative causes of thrombocytopenia can be (c) 2019 Georg Thieme Verlag KG Stuttgart · New York
DOI https://doi.org/

10.1055/s-0039-1678739. ISSN 0720-9355. 
Table 1 Summary of laboratory investigations recommended by international guidelines (top) and summary of investigations discussed in this review (bottom)

\begin{tabular}{|l|}
\hline $\begin{array}{l}\text { Recommended laboratory investigations to exclude an } \\
\text { alternative diagnosis }\end{array}$ \\
\hline Full blood count and film \\
\hline Reticulocytes \\
\hline Lymphocyte subsets \\
\hline Renal, liver and bone profile \\
\hline Thyroid tests (TSH) \\
\hline Dilute Russell's venom viper time (dRVVT) \\
\hline Immunoglobulin levels \\
\hline Serological markers for HIV, HCV and HBV \\
\hline Autoimmune profile: ANA, antiphospholipid antibodies \\
\hline Helicobacter pylori (e.g. breath test) \\
\hline $\begin{array}{l}\text { Available laboratory investigations to confirm the } \\
\text { diagnosis of ITP }\end{array}$ \\
\hline + Full blood count and film \\
\hline+ Immature platelet fraction/reticulated platelets \\
\hline+ Platelet autoantibodies in a direct GP-specific test \\
\hline ? Platelet-specific complement activation \\
\hline ? Thrombopoietin level \\
\hline - Plasma glycocalicin level \\
\hline - Bone marrow examination \\
\hline
\end{tabular}

Abbreviations: ANA, antinuclear antibodies; GP, glycoprotein; HBV, hepatitis B virus; $\mathrm{HCV}$, hepatitis C virus; HIV, human immunodeficiency virus; ITP, immune thrombocytopenia; TSH, thyroid-stimulating hormone. Note: The '+' sign indicates a recommended test and '-' a non-recommended test. The '?' symbol indicates that the diagnostic relevance of TPO levels, when performed in addition to immature platelet fraction/reticulated platelets, is currently unclear, as is the use of platelet-specific complement activation assays.

difficult and requires comprehensive expertise in platelet disorders. In addition, some treatment options for ITP come with a high cost burden and require long-term treatment, others are less expensive but associated with significant side-effects. Hence, consistent and reliable laboratory criteria would help to overcome both incorrect diagnoses and inadequate pharmacotherapy. Laboratory investigations with a potential of confirming the diagnosis of ITP rather than only excluding other diagnoses have been developed ( - Table 1 ); these will be discussed in this review in two sections: tests aiming to detect platelet autoantibodies, and tests aiming to discriminate between accelerated destruction and decreased production of platelets.

\section{Detection of Platelet Autoantibodies}

\section{General Considerations}

Demonstrating the presence of a target-specific antibody, together with typical clinical features, is the mainstay in diagnosing a large variety of autoimmune disorders. ${ }^{4}$ It is difficult to pinpoint what exactly led to the disregard of this approach in ITP. One relevant factor might have been early guidelines which, based on expert opinion rather than on scientific evidence, proposed to not use antibody detection methods. ${ }^{5}$ Incomplete knowledge of diagnostic methods appears to be another relevant reason why these tests are disregarded. As an example, the International Experts Guideline states that 'glycoprotein-specific antibody testing ... [is] not routinely recommended because platelet-associated IgG is elevated in immune and non-immune thrombocytopenia'; $^{2}$ two different test methods are mixed up, of which one (platelet-associated immunoglobulin G [PAIgG]) is extremely non-specific, whereas the other (glycoprotein [GP]-specific antibody testing) is highly specific. The differences between these two types of tests and their utility in diagnosing ITP are discussed in the following section.

\section{Platelet-Associated Immunoglobulin G}

Since platelet destruction is mainly driven by IgG antibodies directed toward platelet surface antigens, the first type of assays looked at the amount of $\operatorname{IgG}$ present on a platelet. ${ }^{6}$ Various methodologies were reported, including, direct platelet immunofluorescence test (PIFT) and competitive enzyme-linked immunoassay (CELIA). ${ }^{7,8}$ It soon became clear that increased IgGs can be detected on platelets both from patients with ITP non-immune mediated thrombocytopenic conditions. ${ }^{9}$ The increased absorption of IgG (and other plasma proteins) appears to be in equilibrium with plasma, with the IgG amount per platelet increasing as the overall number of platelets decreases. ${ }^{10}$ With a documented specificity between 19 and 77\% (-Table 2), it is now generally accepted that PAIgG is an inappropriate test for the diagnosis of ITP.

However, the direct PIFT shows some correlation with direct GP-specific tests ${ }^{11}$ suggesting the presence of 'true' GP-specific IgG between all the other immunoglobulins on a platelet surface ( - Fig. 1A). Based on these and other observations, some authors suggested an initial screen by direct PIFT before a GP-specific assay is being performed. The rate of false-negative direct PIFT results (i.e. where a GP-specific antibody was detected by a GP-specific test despite a

Table 2 Test characteristics of platelet-associated IgG (PAlgG) with different methods

\begin{tabular}{|l|l|l|l|l|}
\hline Author & $\begin{array}{l}\text { No. of patients } \\
\text { (no. of controls) }\end{array}$ & Method & Sensitivity & Specificity \\
\hline $\begin{array}{l}\text { Kelton and } \\
\text { Steeves }\end{array}$ & $\begin{array}{l}68 \\
(101)\end{array}$ & RIA & 91 & 27 \\
\hline $\begin{array}{l}\text { Brighton } \\
\text { et al }\end{array}$ & $\begin{array}{l}18 \\
(53)\end{array}$ & $\begin{array}{l}\text { CELIA } \\
\text { ELISA }\end{array}$ & $\begin{array}{l}74 \\
34\end{array}$ & $\begin{array}{l}26 \\
77\end{array}$ \\
\hline $\begin{array}{l}\text { Warner } \\
\text { et al }\end{array}$ & $\begin{array}{l}15 \\
(32)\end{array}$ & IRMA & 78 & 19 \\
\hline $\begin{array}{l}\text { Fabris } \\
\text { et al }\end{array}$ & $\begin{array}{l}65 \\
(39)\end{array}$ & FACS & 60 & 77 \\
\hline
\end{tabular}

Abbreviations: CELIA, competitive enzyme-linked immunoassay; ELISA, enzyme-linked immunosorbent assay; FACS, flow cytometry; IRMA, immunoradiometric assay; RIA, radioimmunoassay. Note: Refer to the original papers for technical details. 


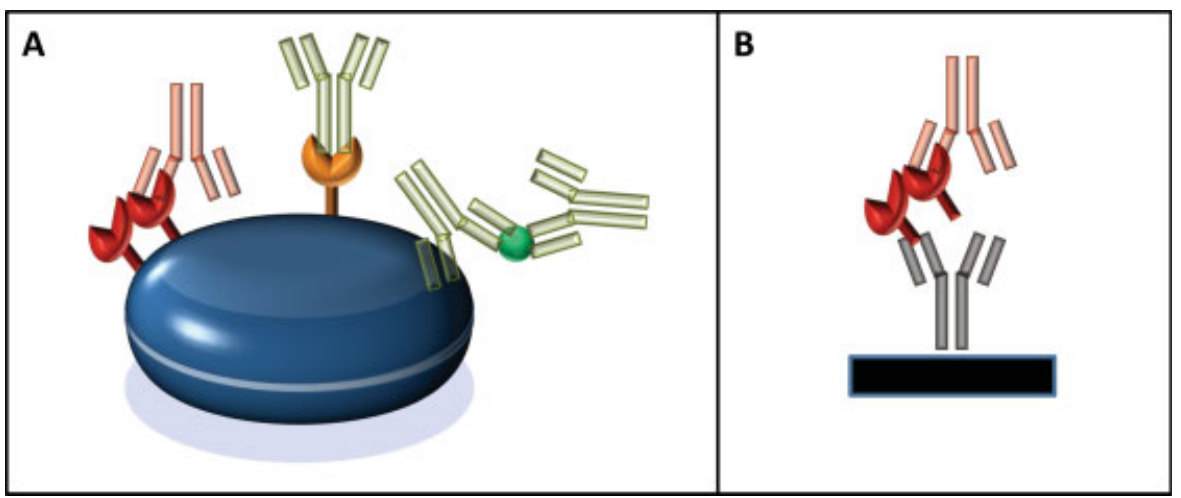

Fig. 1 Schematic representation of platelet autoantibodies and other immunoglobulins present on a platelet. (A) Platelet-associated IgG (PAlgG) includes, besides IgG inside the platelet (not shown), platelet autoantibodies against glycoproteins, which are specific for ITP (red), but also other $\mathrm{lgG}$ molecules which are absorbed on the platelet surface, e.g. as immune complexes (green). A typical PAlgG assay detects all types of immunoglobulins. (B) Glycoprotein-specific tests detect glycoprotein-specific autoantibodies in a tri-molecular complex consisting of the platelet autoantibody (red), the target glycoprotein (red) and a monoclonal capture antibody (grey) which anchors the complex on a carrier material such as a microtitre plate or a bead. After washings, the presence of the platelet autoantibody is visualized with a secondary anti-human antibody which is labelled (e.g. with an enzyme); the secondary antibody is not shown. IgG, immunoglobulin G; ITP, immune thrombocytopenia.

negative initial screen by direct PIFT) ranges from null to $25 \%{ }^{12,13}$ A variation of the classical PAIgG method was recently published ${ }^{14}$ where eluates with glycine were prepared from patient samples, then incubated with test platelets and, after the addition of fluorescence-labelled anti-IgG, finally analysed on a flow cytometer, with a reported $\sim 70 \%$ sensitivity. This study lacks a non-immune thrombocytopenic control group and the specificity may not be any different to previous reports. At this point in time, PAIgG across methods should neither be used as a diagnostic test for ITP, nor for screening prior to applying GP-specific tests.

\section{Direct Glycoprotein-Specific Assays for Platelet Autoantibody Detection}

A break-through in identifying platelet autoantibodies as a distinct entity was the development of the monoclonal antibody immobilization test for platelet antigens (MAIPA) assay and its somewhat comparable counterpart, the immunobead assay. ${ }^{15-17}$ These assays can measure autoantibodies in complex with their cognate GP as direct assays. Complexes of autoantibodies together with their target GPs are taken out of the patient's platelet membranes and immobilized to a carrier in a GP-specific way (-Fig. 1B). One of the most relevant prospective studies with a GP-specific assay came from Brighton et $\mathrm{al}^{18}$ who used the direct MAIPA in 94 ITP patients, and noted a sensitivity of $49 \%$ and a specificity of $78 \%$. A drawback of this study was the inclusion of patients with lymphoproliferative disorders as a control (non-ITP) group, who may have developed secondary ITP, and thus, may have increased the rate of false positives. Excluding this group of patients, Warner and colleagues ${ }^{15}$ used the direct MAIPA and an antigen capture assay in 81 patients and reported 66\% sensitivity and a much higher specificity of $92 \%$. High specificity and intermediate sensitivity are the quality characteristics of GP-specific tests in many studies. Ten studies applied direct GP-specific test methods in patients and thrombocytopenic controls ( - Table 3); nine of them included 613 ITP patients and 460 controls, and test sensitivity ranged from 39 to $96 \%$ (weighted average:
63\%), and test specificity was between 72 and $100 \%$ (weighted average: 98\%). These cumulative numbers are interesting because they are close to the data presented in the largest single study which came from McMillan and colleagues. ${ }^{19}$ In this prospective analysis of 282 ITP patients, test sensitivity was $55.4 \%$ and test specificity was $84.4 \%$ for the whole group. The specificity rose to $93.1 \%$ when clinical factors consistent with ITP were considered. ${ }^{19}$

Current evidence underlines that direct GP-specific assays have a definite place in the diagnostic work-up of ITP patients, since a positive test result is a very strong diagnostic indicator for the presence of ITP.

\section{Additional Information from Direct Glycoprotein-Specific Tests}

A positive test result in a GP-specific assay is a reliable predictor for the presence of ITP, but can these tests provide additional information of clinical relevance? Only few data on the potential relevance of antibody levels are available. A non-significant trend toward higher direct MAIPA positivity was noted in patients with lower platelet counts, ${ }^{18}$ but no such correlation between the degree of assay positivity and the platelet count was detected in a much larger prospective trial. ${ }^{19}$ Apparently, a correlation between the antibody level and ITP disease activity has not been demonstrated so far. Some prospective studies have indicated that antibody levels could be higher early in disease, ${ }^{19,20}$ but do not yet allow to conclude that an early GPspecific test early would result in better sensitivity.

The potential relevance of antibody specificities has been investigated in more detail. Generally speaking, when patients with platelet autoantibodies of anti-GP IIb/IIIa and anti-GP Ib/ IX specificity are compared, patients with anti-GP Ib/IX appear to have a less favourable outcome following intravenous immunoglobulin therapy or treatment with steroids, with a relative risk for treatment failure of 2.2 to 7.4 ( - Table 4 ). If these results were confirmed, GP-specific tests would not only help to establish the diagnosis of ITP, but also assist in tailoring the therapy for ITP patients. 
Table 3 Test characteristics of different direct glycoprotein-specific methods

\begin{tabular}{|c|c|c|c|c|c|}
\hline Author & $\begin{array}{l}\text { No. of patients } \\
\text { (no. of controls) }\end{array}$ & $\mathrm{S}$ & Method & Sensitivity & Specificity \\
\hline He et $a^{22}$ & $\begin{array}{l}47 \\
(43)\end{array}$ & $\mathrm{E}$ & Immunobead (GAM) & 85 & 97.7 \\
\hline Kiefel et $\mathrm{al}^{25}$ & $\begin{array}{l}78 \\
(100)\end{array}$ & $P$ & $\begin{array}{l}\text { dMAIPA } \\
(G A M)\end{array}$ & 52.6 & 100 \\
\hline Brighton et al ${ }^{18}$ & $\begin{array}{l}94 \\
(53)\end{array}$ & $P$ & dMAIPA & 47 & 85 \\
\hline Hurlimann-Forster et $\mathrm{al}^{24}$ & $\begin{array}{l}82 \\
(37) \\
\end{array}$ & $\mathrm{E}$ & ELISA & 92.7 & 100 \\
\hline Warner et al ${ }^{15}$ & $\begin{array}{l}49 \\
(32) \\
\end{array}$ & $\begin{array}{l}\mathrm{P} \\
\mathrm{P}\end{array}$ & $\begin{array}{l}\text { dMAIPA } \\
\text { AC }\end{array}$ & $\begin{array}{l}39 \\
39 \\
\end{array}$ & $\begin{array}{l}91 \\
91 \\
\end{array}$ \\
\hline Warner et al ${ }^{15}$ & $\begin{array}{l}56 \\
(26)\end{array}$ & $P$ & $A C$ & 66 & 92 \\
\hline Fabris et al ${ }^{12}$ & $\begin{array}{l}65 \\
(39)\end{array}$ & $\mathrm{P}$ & MACE & 60 & 97.5 \\
\hline McMillan et al ${ }^{19}$ & $\begin{array}{l}282 \\
(289) \\
\end{array}$ & $\mathrm{P}$ & Immunobead & 55.4 & $84.4-93.1$ \\
\hline Kuwana et al ${ }^{37}$ & $\begin{array}{l}46 \\
(16)\end{array}$ & $\begin{array}{l}E \\
B\end{array}$ & $\begin{array}{l}\text { ELISA } \\
\text { ELISPOT }\end{array}$ & $\begin{array}{l}61 \\
93\end{array}$ & $\begin{array}{l}88 \\
81\end{array}$ \\
\hline Chen et $\mathrm{al}^{28}$ & $\begin{array}{l}64 \\
(65)\end{array}$ & $\begin{array}{l}\mathrm{P} \\
\mathrm{B}\end{array}$ & $\begin{array}{l}\text { dMAIPA } \\
\text { ELISPOT }\end{array}$ & $\begin{array}{l}39.1 \\
68.8\end{array}$ & $\begin{array}{l}81.8 \\
90.9\end{array}$ \\
\hline He et $\mathrm{al}^{48}$ & $\begin{array}{l}50 \\
(49)\end{array}$ & $\begin{array}{l}P \\
P\end{array}$ & $\begin{array}{l}\text { MAIPA } \\
\text { immunobead-FACS }\end{array}$ & $\begin{array}{l}44 \\
96\end{array}$ & $\begin{array}{l}76.7 \\
72.1\end{array}$ \\
\hline
\end{tabular}

Abbreviations: AC, antigen capture assay; dMAIPA, direct monoclonal antibody immobilization of platelet antigen assay; ELISA, enzyme-linked immunosorbent assay; ELISPOT, enzyme-linked immunospot assay; FACS, flow cytometry; GP, glycoprotein; MACE, modified antigen capture ELISA. Note: This overview includes only studies with appropriate control groups and complete datasets. Studies which did not use GP-specific direct assays and studies with children were excluded. ' $\mathrm{S}$ ' indicates the type of specimen that was analysed ( $\mathrm{E}=$ eluate; $\mathrm{P}=$ platelets or platelet lysate; $\mathrm{B}=\mathrm{B}$ cells). GAM indicates methods by which IgG, IgA and IgM antibodies could be detected. Refer to the original papers for technical details. Note that none of the studies has investigated the presence of autoantibodies against all known immune targets; most studies were in fact restricted to GP IIb/Illa.

Table 4 Clinical studies investigating the potential relevance of platelet autoantibody specificities

\begin{tabular}{|c|c|c|c|c|}
\hline Author & $n$ & Study type & Observation & RR \\
\hline Hasegawa et al ${ }^{50}$ & 38 & $\begin{array}{l}\text { Bone marrow } \\
\text { aspiration }\end{array}$ & $\begin{array}{l}\text { With anti-GP Ib/IX, Megs are smaller and } \\
\text { not increased in numbers }\end{array}$ & - \\
\hline Levy et $a^{49}$ & 14 & \multirow[t]{3}{*}{ IVIG } & $\begin{array}{l}\text { No differences between anti-GP IIb/IIIa and } \\
\text { anti-Ib/IX in response }\end{array}$ & - \\
\hline Go et $a^{51}$ & 17 & & With anti-GP Ib/IX poor response & 3.3 \\
\hline Peng et a ${ }^{52}$ & 156 & & With anti-GP Ib/IX poor response & 2.2 \\
\hline Mehta et $\mathrm{al}^{53}$ & 208 & \multirow[t]{2}{*}{ Steroids } & $\begin{array}{l}\text { With anti-GP Ib/IX plus anti-GP IIb/IIla less } \\
\text { often CR than with anti-GP IIb/IIla only }\end{array}$ & 7.4 \\
\hline Zeng et $\mathrm{al}^{54}$ & 176 & & With anti-GP Ib/IX poor response & 2.7 \\
\hline
\end{tabular}

Abbreviations: CR, ...; GP, glycoprotein; IVIG, intravenous immunoglobulins.

Note: The relative risk (RR) was calculated from data provided in the papers, whenever possible. Note that with one exception (Levy et al ${ }^{49}$ ) all studies demonstrate a less favourable outcome for patients with autoantibodies against GP Ib/IX. n: number of patients.

\section{Why Do Glycoprotein Specific Tests Lack Sensitivity?}

GP-specific tests are highly specific for ITP and may even have the potential to specifically predict treatment outcome, but are of low sensitivity, missing roughly half of all patients with ITP ( - Table 2). One group of factors for this failure may lie outside the test itself. First, test-negative ITP patients may have a predominant mechanism of platelet destruction which does not involve platelet autoantibodies. Second, pre-test treatment regimens may have strong effects on the antibody levels, lowering them below the test's limit of detection. ${ }^{21}$ Third, too few platelets for testing are a relevant pre-analytical problem; in Brighton's landmark trial, ${ }^{18}$ a relevant number of patients had to be excluded because the platelet counts were too low for testing. 
Another group of factors are those related to the construction of the assays itself. The selection of target antigens (other than GP IIb/IIIa and GP Ib/IX), the monoclonal antibody clone and the type of the secondary antibody seem to have only minor influence on the test performance, if any. Usually, target antigens which become immobilized are restricted to GP IIb/IIIa and GP Ib/IX. However, if other antigens are tested, such as GP Ia/IIa, the sensitivity does not increase significantly, although some conflicting data were reported. $^{22,23}$ In theory, relevant additional target antigens may have been overlooked, but this is speculative. Since the platelet autoantibody and the monoclonal antibody that immobilizes the GP to a carrier bind to the same antigen (-Fig. 1B), steric hindrance has been brought forward as an issue, but is considered to be unlikely by experts in the field. ${ }^{19}$ Finally, most assays identify IgG antibodies only. This seems to be another minor issue since platelet autoantibodies of classes other than IgG are very rarely detected. In an enzyme-linked immunosorbent assay (ELISA) system, one IgM only was detected in 76 positive platelet eluates. ${ }^{24}$ In a modified MAIPA test using platelet eluates, ${ }^{25} 1 / 21$ (4.7\%) was not of the IgG type. In a more recent direct flow assay, 2/23 platelets from ITP patients carried IgA + IgM and no IgG. ${ }^{26}$ It should be noted that none of the studies has confirmed that antibody specificities other than IgG are capable of eliminating platelets.

A more relevant shortcoming of current test systems appears to be the inevitable washing, because low-avidity antibodies seem to become washed off easily and thus escape detection, ${ }^{27}$ indicating that assays with less wash steps could be advantageous. Further work needs to be invested in the field.

\section{B Cell Assays}

A different way to look at GP-specific antibodies which largely avoids washing is the demonstration of specific B cells in an enzyme-linked immunospot (ELISPOT) assay. Circulating B cells secreting anti-GP IIb/IIIa antibodies in the peripheral blood of ITP patients are memory $B$ cells and reflect the autoantibody response in the spleen. Several studies analysing these B cells were conducted ${ }^{28-31}$ and reported sensitivities between 84 and $90 \%$, and specificities around $90 \%$. The most recent study revealed a sensitivity of $69 \%$ and a specificity of $91 \%{ }^{28}$ Apparently, ELISPOT has a higher sensitivity than the classical GP-specific tests, but its specificity is slightly lower. This may be related to the fact that setting the optimal cut-off was delicate in the studies, because B cells from healthy controls often produced signals: in one study, ${ }^{32} 42 \%$ of the controls versus $84 \%$ of the ITP group had anti-GP IIb/IIIa signals in the ELISPOT assay, explaining a loss of specificity.

\section{Indirect Glycoprotein-Specific Assays}

The use of assays which detect free GP-specific autoantibodies in patient plasma or serum should be generally disapproved, since free platelet autoantibodies are only detectable in a small minority of patients who carry autoantibodies bound to their platelets. Such an approach has a very low sensitivity and is always inferior to a direct GPspecific test. ${ }^{33,34}$ However, in some ITP patients with very low platelet counts, a direct test cannot be performed, and a positive indirect test may be considered helpful.

\section{Commercially Available Assays for Autoantibodies}

The author is not aware of studies which have directly compared GP-specific in-house tests with commercially available test systems. Commercial tests are usually based on the use of eluates which are prepared from the patient's platelets and are then brought together with isolated GPs immobilized on a carrier. A major concern is the strong dependency of autoantibodies on intact GP complexes: ${ }^{35}$ isolation of GPs may easily destroy epitopes or create new ones, which would interfere with the test characteristics. A specificity of only $58 \%$ was reported for the PakAutoAssay, ${ }^{23}$ which is very low compared with other studies ( - Table 3 ) and might indicate test-related problems. However, comparative testing was not performed, and the cohort included pediatric samples. Another recent study comparing commercially available ELISA or solid-phase assays concluded that in cases of suspected ITP, a direct MAIPA should be preferred. ${ }^{34}$

\section{Other Laboratory Tests}

\section{General Considerations}

The discrimination between accelerated destruction and decreased production of platelets is the central idea behind most other tests that were assessed over the past decades. With the technical progress of haematology analysers, immature platelets are now being used more widely, and they can be considered as a significant progress in the diagnostic work-up of ITP patients.

\section{Reticulated Platelets/Immature Platelet Fraction}

Kienast and Schmitz ${ }^{36}$ were the first to report the use of thiazole orange (TO), a fluorescent nucleic acid dye originally synthesized for reticulocyte analysis, with platelets. They reported a high percentage of fluorescently labelled platelets in patients with increased platelet destruction (13-57\%), whereas the proportion of stained platelets in patients with thrombocytopenia due to impaired platelet production did not differ from healthy controls (3-16\%). This sensitive and specific test can rapidly provide information on the thrombopoietic activity in patients with low platelet counts. Somewhat comparable results came later from a more complex study including reticulated platelets using TO staining, ${ }^{37}$ which together with absence of anaemia and leukopenia gave a sensitivity of $83 \%$ and a specificity of $88 \%$. The limited availability of flow cytometers in diagnostic laboratories may have hampered its broader use. Now, for some years, the immature platelet fraction (IPF) has been made available on routine haematology analysers, and a recent analysis indicates that, at a $7 \%$ IPF decision value, sensitivity was $85 \%$ and specificity was 70\% for ITP. ${ }^{38}$ This study included 62 ITP patients and 169 controls, where the mean IPF\% was $16.39 \%( \pm 11.15)$ in ITP patients and $7.69 \%( \pm 6.09)$ in controls. Since IPF is inexpensive and available from routine instrumentation in many laboratories, it should be considered one of the relevant initial investigations in any patient with thrombocytopenia. 


\section{Thrombopoietin}

Thrombopoietin (TPO) is the major regulator of platelet production. The rate of megakaryopoiesis and the amount of circulating platelets correlate inversely with TPO levels. Patients with mainly consumptive thrombocytopenic disorders including ITP have normal or only mildly elevated TPO levels, whereas patients with other causes have high TPO levels. ${ }^{39}$ Several commercial assays with significantly different characteristics are available. In a thoroughly performed study by Makar et al, ${ }^{40}$ the reference range was 7 to $99 \mathrm{pg} / \mathrm{mL}$, and at decision level greater than $110 \mathrm{pg} / \mathrm{mL}$, consumptive thrombocytopenia could be differentiated from hypoproliferative types with a specificity of $85 \%$ and a sensitivity of $90 \%$. The same group has later postulated that by the use of TPO levels, a diagnosis of typical ITP can be validated. ${ }^{41}$ Apparently, the TPO level is a promising parameter. Measuring the TPO level is inexpensive, but not available from routine laboratories. A multicentre trial in which several parameters were studied in ITP patients indicated that measuring TPO within a set of tests increases sensitivity, but lowers specificity of the diagnostic algorithm. ${ }^{32}$ In another trial, adding TPO levels to reticulated platelets as a diagnostic marker decreased sensitivity but increased specificity. ${ }^{42}$ Additional data are required before a clear statement on the clinical utility of this test can be made.

\section{Platelet Glycocalicin}

Platelet glycocalicin (GC) is the extramembranous part of platelet GP Ibalpha that can be rapidly cleaved from the surface; it has been proposed as a marker reflecting platelet turnover. ${ }^{43}$ It has been extensively studied for several disorders. The so-called GC index (GC normalized for a platelet count) was able to discriminate patients with active ITP from other thrombocytopenic patients ${ }^{44}$ in a follow-up study, ${ }^{45}$ establishing a normal range for the GC index of $0.8 \pm 0.16$ in 60 healthy controls and a cut-off of 1.12 resulted in a specificity of $96 \%$ and a sensitivity of $98 \%$ for ITP. However, the number of non-immune thrombocytopenic patients was very low in this study. In a subsequent study, Kurata and colleagues ${ }^{42}$ investigated GC levels in 65 ITP patients, 20 patients with aplastic anaemia, and 22 patients with chemotherapy-induced low platelet counts. The authors reported a sensitivity of $87 \%$, but a specificity of only $40 \%$ for the GC index. This was mainly attributed to the unexpectedly high GC levels in chemotherapy patients with low platelet counts; tumour cell lysis with the release of elastases may have elevated the GC level. Others have previously reported that GC levels in individual patients were found to be too widely spread to be used as a diagnostic marker. ${ }^{39}$ Therefore, plasma GC levels and the GC index may have little diagnostic value for distinguishing ITP from other thrombocytopenias.

\section{Bone Marrow Examination}

A bone marrow examination (BME) is not diagnostic for ITP. However, it is still frequently performed, and the recently reported discrepancy between the percentage of blood films that were not done (25\%) and the number of unnecessary BMEs that were performed without need (50\%) seems to indicate that this investigation is still considered diagnostic by a relevant number of physicians. ${ }^{46}$ Less than $25 \%$ of all BMEs reveal typical features of ITP. ${ }^{47}$ BMEs were considered to be unreliable and frequently non-diagnostic; accordingly, they should only be performed as a successive test of exclusion, and only atypical results in the initial assessment of the patient (especially, abnormal haematology tests, a large spleen or the presence of lymph nodes) should trigger a bone marrow aspiration. Age above 65 years has been suggested as an independent trigger. ${ }^{3}$ No data have been published from trials in which IPF, TPO levels and BME data were collected, but it is intriguing to speculate that other indicators of bone marrow function will further reduce the number of bone marrows in clinical practice.

\section{Combined Laboratory Test Results}

Most of the above-mentioned studies have used test results as single decision criteria to diagnose ITP. Kurata and coworkers $^{42}$ have nicely demonstrated that the combined use of reticulated platelets and TPO levels is very helpful to discriminate destructive from hypoplastic thrombocytopenia. An even more sophisticated tool was proposed by Kuwana et $\mathrm{al}^{37}$ which included six parameters: absence of anaemia, absence of leukopenia, increased frequency of anti-GP IIb/ IIla producing B cells, presence of anti-IIb/IIIa in a GP-specific test, elevated percentage of reticulated platelets and normal or slightly increased TPO levels. This combination of ITPassociated laboratory findings was rated positive if three or more criteria were fulfilled. In a monocentre study, this approach gave a sensitivity of $96 \%$ and a specificity of $94 \%$ for diagnosing ITP. In a subsequent multicentre study, ${ }^{32}$ the same tool gave $98 \%$ sensitivity and $79 \%$ specificity, with the decrease in specificity being mainly explained by several patients what had a myelodysplastic syndrome (MDS)/ITP overlap syndrome. These studies indicate that developing diagnostic criteria for ITP is feasible and valuable.

\section{Conclusion}

ITP is not a diagnosis of exclusion. As with other autoimmune diseases, detection of a characteristic autoantibody proves the diagnosis of ITP. As outlined in this review, only the direct GP-specific test (direct MAIPA or direct immunobead assay) has the properties that are required to demonstrate such a characteristic autoantibody. There is no scientific evidence to support methods which measure PAIgG (not even as a screening test) and there is no evidence to support any indirect (plasma- or serum-based) antibody detection method. Only sparse data are available for commercial capture assays and their use is currently not endorsed outside scientific studies. Demonstrating the presence of platelet autoantibodies should be performed as part of the initial assessment, since a positive test result establishes a sound basis for further diagnostic procedures and treatment.

A significant drawback of direct GP-specific tests is their low sensitivity, and a negative test result has no relevance. It is therefore useful to establish a diagnosis of (primarily) hyperdestructive thrombocytopenia early in the patient's 
assessment. A full blood count together with the IPF (or percentage of reticulated platelets) has an excellent positive predictive value for ITP and should always be performed in patients presenting with unexplained low platelet counts. Plasma GC has no apparent diagnostic value in identifying ITP patients, and conflicting data for TPO preclude its use for diagnostic purposes. In future, more prospective trials incorporating potential diagnostic markers are required, and serologists are in demand for developing antibody detection systems with increased sensitivity.

Conflict of Interest

None.

\section{References}

1 Neunert C, Lim W, Crowther M, Cohen A, Solberg L Jr, Crowther MA; American Society of Hematology. The American Society of Hematology 2011 evidence-based practice guideline for immune thrombocytopenia. Blood 2011;117(16):4190-4207

2 Provan D, Stasi R, Newland AC, et al. International consensus report on the investigation and management of primary immune thrombocytopenia. Blood 2010;115(02):168-186

3 Cooper N. State of the art - how I manage immune thrombocytopenia. Br J Haematol 2017;177(01):39-54

4 Castro C, Gourley M. Diagnostic testing and interpretation of tests for autoimmunity. J Allergy Clin Immunol 2010;125(02, Suppl 2): S238-S247

5 George JN, Woolf SH, Raskob GE, et al. Idiopathic thrombocytopenic purpura: a practice guideline developed by explicit methods for the American Society of Hematology. Blood 1996;88(01):3-40

6 Dixon R, Rosse W, Ebbert L. Quantitative determination of antibody in idiopathic thrombocytopenic purpura. Correlation of serum and platelet-bound antibody with clinical response. $\mathrm{N}$ Engl J Med 1975;292(05):230-236

7 von dem Borne AE, Verheugt FW, Oosterhof F, von Riesz E, de la Rivière $A B$, Engelfriet $C P$. A simple immunofluorescence test for the detection of platelet antibodies. Br J Haematol 1978;39(02):195-207

8 Kiefel V, Jäger S, Mueller-Eckhardt C. Competitive enzyme-linked immunoassay for the quantitation of platelet-associated immunoglobulins (IgG, IgM, IgA) and complement (C3c, C3d) with polyclonal and monoclonal reagents. Vox Sang 1987;53(03):151-156

9 Mueller-Eckhardt C, Kayser W, Mersch-Baumert K, et al. The clinical significance of platelet-associated IgG: a study on 298 patients with various disorders. Br J Haematol 1980;46(01):123-131

10 Kelton JG, Steeves K. The amount of platelet-bound albumin parallels the amount of IgG on washed platelets from patients with immune thrombocytopenia. Blood 1983;62(04):924-927

11 Joutsi L, Kekomäki R. Comparison of the direct platelet immunofluorescence test (direct PIFT) with a modified direct monoclonal antibody-specific immobilization of platelet antigens (direct MAIPA) in detection of platelet-associated IgG. Br J Haematol 1997;96(01):204-209

12 Fabris F, Scandellari R, Randi ML, Carraro G, Luzzatto G, Girolami A. Attempt to improve the diagnosis of immune thrombocytopenia by combined use of two different platelet autoantibodies assays (PAIgC and MACE). Haematologica 2002;87(10):1046-1052

13 Hézard N, Simon G, Macé C, Jallu V, Kaplan C, Nguyen P. Is flow cytometry accurate enough to screen platelet autoantibodies? Transfusion 2008;48(03):513-518

14 Teraz-Orosz A, Cooper N, Crawley JTB, Salles-Crawley II. Detection of anti-platelet antibodies in immune thrombocytopenia by flow cytometry. Br J Haematol 2018 ( e-pub ahead of print). Doi: 10.1111/bjh.15187
15 Warner MN, Moore JC, Warkentin TE, Santos AV, Kelton JG. A prospective study of protein-specific assays used to investigate idiopathic thrombocytopenic purpura. Br J Haematol 1999;104 (03):442-447

16 Kiefel V, Santoso S, Weisheit M, Müeller-Eckhardt C. Monoclonal antibody-specific immobilization of platelet antigens (MAIPA): a new tool for the identification of platelet-reactive antibodies. Blood 1987;70(06):1722-1726

17 McMillan R, Tani P, Millard F, Berchtold P, Renshaw L, Woods VL Jr. Platelet-associated and plasma anti-glycoprotein autoantibodies in chronic ITP. Blood 1987;70(04):1040-1045

18 Brighton TA, Evans S, Castaldi PA, Chesterman CN, Chong BH. Prospective evaluation of the clinical usefulness of an antigenspecific assay (MAIPA) in idiopathic thrombocytopenic purpura and other immune thrombocytopenias. Blood 1996;88(01):194-201

19 McMillan R, Wang L, Tani P. Prospective evaluation of the immunobead assay for the diagnosis of adult chronic immune thrombocytopenic purpura (ITP). J Thromb Haemost 2003;1(03):485-491

20 Zhai J, Ding M, Yang T, et al. Flow cytometric immunobead assay for quantitative detection of platelet autoantibodies in immune thrombocytopenia patients. J Transl Med 2017;15(01):214

21 Arnold DM, Vrbensky JR, Karim N, et al. The effect of rituximab on anti-platelet autoantibody levels in patients with immune thrombocytopenia. Br J Haematol 2017;178(02):302-307

22 He R, Reid DM, Jones CE, Shulman NR. Spectrum of Ig classes, specificities, and titers of serum antiglycoproteins in chronic idiopathic thrombocytopenic purpura. Blood 1994;83(04):1024-1032

23 Davoren A, Bussel J, Curtis BR, Moghaddam M, Aster RH, McFarland JG. Prospective evaluation of a new platelet glycoprotein (GP)-specific assay (PakAuto) in the diagnosis of autoimmune thrombocytopenia (AITP). Am J Hematol 2005;78(03):193-197

24 Hurlimann-Forster M, Steiner B, von Felten A. Quantitation of platelet-specific autoantibodies in platelet eluates of ITP patients measured by a novel ELISA using the purified glycoprotein complexes GPIIb/IIIa and GPIb/IX as antigens. Br J Haematol 1997;98 (02):328-335

25 Kiefel V, Freitag E, Kroll H, Santoso S, Mueller-Eckhardt C. Platelet autoantibodies (IgG, IgM, IgA) against glycoproteins IIb/IIIa and Ib/IX in patients with thrombocytopenia. Ann Hematol 1996;72 (04):280-285

26 Nishioka T, Yamane T, Takubo T, Ohta K, Park K, Hino M. Detection of various platelet-associated immunoglobulins by flow cytometry in idiopathic thrombocytopenic purpura. Cytometry B Clin Cytom 2005;68(01):37-42

27 Najaoui A, Bakchoul T, Stoy J, et al. Autoantibody-mediated complement activation on platelets is a common finding in patients with immune thrombocytopenic purpura (ITP). Eur J Haematol 2012;88(02):167-174

28 Chen JF, Yang LH, Chang LX, Feng JJ, Liu JQ. The clinical significance of circulating B cells secreting anti-glycoprotein IIb/IIIa antibody and platelet glycoprotein IIb/IIIa in patients with primary immune thrombocytopenia. Hematology 2012;17(05):283-290

29 Satoh T, Pandey JP, Okazaki Y, et al. Single nucleotide polymorphisms of the inflammatory cytokine genes in adults with chronic immune thrombocytopenic purpura. Br J Haematol 2004;124 (06):796-801

30 Kuwana M, Okazaki Y, Kaburaki J, Kawakami Y, Ikeda Y. Spleen is a primary site for activation of platelet-reactive $T$ and $B$ cells in patients with immune thrombocytopenic purpura. J Immunol 2002;168(07):3675-3682

31 Kuwana $\mathrm{M}$, Kaburaki J, Kitasato $\mathrm{H}$, et al. Immunodominant epitopes on glycoprotein IIb-IIIa recognized by autoreactive $\mathrm{T}$ cells in patients with immune thrombocytopenic purpura. Blood 2001;98(01):130-139

32 Kuwana M, Kurata Y, Fujimura K, et al. Preliminary laboratory based diagnostic criteria for immune thrombocytopenic purpura: evaluation by multi-center prospective study. J Thromb Haemost 2006;4(09):1936-1943 
33 Berchtold P, Müller D, Beardsley D, et al. International study to compare antigen-specific methods used for the measurement of antiplatelet autoantibodies. Br J Haematol 1997;96(03):477-483

34 Sareban N, Macher S, Drexler C, Posch U, Lanzer G, Schallmoser K. Platelet antibody analysis by three different tests. J Clin Lab Anal 2015;29(03):198-202

35 Bowditch RD, Tani P, McMillan R. Reactivity of autoantibodies from chronic ITP patients with recombinant glycoprotein IIIa peptides. Br J Haematol 1995;91(01):178-184

36 Kienast J, Schmitz G. Flow cytometric analysis of thiazole orange uptake by platelets: a diagnostic aid in the evaluation of thrombocytopenic disorders. Blood 1990;75(01):116-121

37 Kuwana M, Okazaki Y, Satoh T, Asahi A, Kajihara M, Ikeda Y. Initial laboratory findings useful for predicting the diagnosis of idiopathic thrombocytopenic purpura. Am J Med 2005;118(09):1026-1033

38 Naz A, Mukry SN, Shaikh MR, Bukhari AR, Shamsi TS. Importance of immature platelet fraction as predictor of immune thrombocytopenic purpura. Pak J Med Sci 2016;32(03):575-579

39 Porcelijn L, Folman CC, Bossers B, et al. The diagnostic value of thrombopoietin level measurements in thrombocytopenia. Thromb Haemost 1998;79(06):1101-1105

40 Makar RS, Zhukov OS, Sahud MA, Kuter DJ. Thrombopoietin levels in patients with disorders of platelet production: diagnostic potential and utility in predicting response to TPO receptor agonists. Am J Hematol 2013;88(12):1041-1044

41 Kuter DJ, Meibohm A, Lopez A. TPO concentrations and response to romiplostim. Am J Hematol 2014;89(12):1155-1156

42 Kurata Y, Hayashi S, Kiyoi T, et al. Diagnostic value of tests for reticulated platelets, plasma glycocalicin, and thrombopoietin levels for discriminating between hyperdestructive and hypoplastic thrombocytopenia. Am J Clin Pathol 2001;115(05):656-664

43 Steinberg MH, Kelton JG, Coller BS. Plasma glycocalicin. An aid in the classification of thrombocytopenic disorders. N Engl J Med 1987;317(17):1037-1042

44 Beer JH, Büchi L, Steiner B. Glycocalicin: a new assay-the normal plasma levels and its potential usefulness in selected diseases. Blood 1994;83(03):691-702
45 Steffan A, Pradella P, Cordiano I, Girolami A, De Marco L, Fabris F. Glycocalicin in the diagnosis and management of immune thrombocytopenia. Eur J Haematol 1998;61(02):77-83

46 Lozano ML, Revilla N, Gonzalez-Lopez TJ, et al. Real-life management of primary immune thrombocytopenia (ITP) in adult patients and adherence to practice guidelines. Ann Hematol 2016;95(07):1089-1098

47 Mahabir VK, Ross C, Popovic S, et al. A blinded study of bone marrow examinations in patients with primary immune thrombocytopenia. Eur J Haematol 2013;90(02):121-126

48 He Y, Zhao YX, Zhu MQ, Wu Q, Ruan CG. Detection of autoantibodies against platelet glycoproteins in patients with immune thrombocytopenic purpura by flow cytometric immunobead array. Clin Chim Acta 2013;415:176-180

49 Levy Y, Sherer Y, Ahmed A, et al. Autoantibody level modification in adult patients with idiopathic thrombocytopenic purpura following intravenous immunoglobulin treatment. Nat Immun 1998;16(5-6):207-214

50 Hasegawa Y, Nagasawa T, Kamoshita M, et al. Effects of antiplatelet glycoprotein Ib and/or IIb/IIIa autoantibodies on the size of megakaryocytes in patients with immune thrombocytopenia. Eur J Haematol 1995;55(03):152-157

51 Go RS, Johnston KL, Bruden KC. The association between platelet autoantibody specificity and response to intravenous immunoglobulin $\mathrm{G}$ in the treatment of patients with immune thrombocytopenia. Haematologica 2007;92(02):283-284

52 Peng J, Ma SH, Liu J, et al. Association of autoantibody specificity and response to intravenous immunoglobulin $G$ therapy in immune thrombocytopenia: a multicenter cohort study. J Thromb Haemost 2014;12(04):497-504

53 Mehta YS, Pathare AV, Badakere SS, Ghosh K, Mohanty D. Influence of auto-antibody specificities on the clinical course in patients with chronic and acute ITP. Platelets 2000;11(02):94-98

54 Zeng Q Zhu L, Tao L, et al. Relative efficacy of steroid therapy in immune thrombocytopenia mediated by anti-platelet GPIIbIIIa versus GPIb $\alpha$ antibodies. Am J Hematol 2012;87(02): 206-208 